\title{
Effect of Static Annealing on Microstructure and Texture in Extruded Mg-Gd-Y-Zr Alloy
}

\author{
$\mathrm{Li} \mathrm{Li}^{1,2}, \quad$ Wu Jie${ }^{1}, \quad$ Wu Yuanzhi ${ }^{1}, \quad$ Nguyen Dang Nam ${ }^{2}$ \\ ${ }^{1}$ Hunan Institute of Technology, Hengyang 421002, China; ${ }^{2}$ Deakin University, Geelong, Victoria 3220, Australia
}

\begin{abstract}
The evolution of microstructure and texture for an extruded Mg-9Gd-4Y-0.6Zr alloy during static annealing was investigated. The grain growth, precipitation and texture modification were characterized by optical microscopy, scanning electron microscopy, transmission electron microscopy, XRD texture instrument and EBSD. The results show that the grain refinement at the initial stage of static annealing is caused by recrystallization. The intergranular deformation stimulates local precipitating, which in turn inhibits the recrystallization process. The texture analysis indicates that the hot extrusion produces the conventional basal fiber with $\{0001\} / / \mathrm{ED}$ and the unusual prismatic fiber with $c$ axis // ED. During static recrystallization, the grain nucleation weakens the prismatic fiber, while the grain growth strengthens it. A large number of plate phases precipitate at grain boundaries along with subgrain boundaries, which significantly inhibits the texture modification.
\end{abstract}

Key words: Mg-Gd-Y-Zr alloy; extrusion; static annealing; texture; microstructure

Wrought magnesium alloys have great potential applications in the automotive industry for researchers are interested in using lightweight magnesium as automotive sheet and extrusion for vehicle body ${ }^{[1]}$. So far, a large number of investigations have been made on the relationship of composition, microstructure, texture and mechanical behavior for the wrought $\mathrm{Mg}$ alloys ${ }^{[2-6]}$. It is generally thought that the weakening basal textures can improve the formability of the hcp material. Texture weakening in the alloys is closely related to particle-stimulated nucleation of recrystallization (PSN) ${ }^{[3]}$, solute effects ${ }^{[5]}$, and selective growth of randomly oriented new grains ${ }^{[4,6]}$. It is reported that weak textures can be obtained by the addition of rare earth elements and alkaline earths into binary or ternary $\mathrm{Mg}$ alloys. The underlying mechanism is the generation of second-phase strings that nucleate new recrystallized grains with orientations different from parent grains. Robson et al. ${ }^{[7]}$ reported that an unusual texture component with its $c$-axis parallel to the extrusion direction was generated in a high rare-earth-containing $\mathrm{Mg}$ alloy. In addition, the change of solute solubility at the hot working temperature also influences texture modification, since the increased solute can weaken basal texture via solute drag. In view of current studies, the texture weakening effect is mainly ascribed to solute drag, because the texture is also weakened in the absence of particles ${ }^{[8]}$.

The addition of rare earth (RE) elements into $\mathrm{Mg}$ alloy improves its elevated temperature mechanical properties due to solution hardening and precipitation hardening ${ }^{[9]}$. The mechanical properties of the single-extruded alloy can be further remarkably improved by double extrusion ${ }^{[10]}$. So far, few literatures have been reported on the effect of intermediate annealing on the microstructure and texture evolution of the high containing rare earth alloy. The purpose of the present investigation is to clarify the effect of precipitation during static recrystallization (SRX) on the microstructure and texture evolution of Mg-9Gd-4Y-0.6Zr alloy.

\section{Experiment}

The as-cast ingot with a nominal composition of $\mathrm{Mg}-9 \mathrm{Gd}$ $4 \mathrm{Y}-0.6 \mathrm{Zr}$ was prepared followed by homogenization at $793 \mathrm{~K}$ for $8 \mathrm{~h}$ and subsequent cooling in air. The samples were extruded at $648 \mathrm{~K}$ with an extrusion ratio of $16: 1$ and a

Received date: September 19, 2015

Foundation item: Hunan Provincial Natural Science Foundation of China (11JJ4033); Scientific Research Fund of Hunan Provincial Education Department (12B030) Corresponding author: Li Li, Ph. D., Associate Professor, Institute of Advanced Manufacturing Technology, Hunan Institute of Technology, Hengyang 421002, P. R. China, Tel: 0086-734-3452206, E-mail: lileewin@163.com 
constant RAM speed of $2 \mathrm{~mm} / \mathrm{min}$. Hereafter, ED refers to the extrusion direction, while RD refers to the radial direction of the extruded rods. The microstructure in the plane composed of $\mathrm{ED}$ and $\mathrm{RD}$ was characterized by XJP-6A optical microscope (OM), KYKY2800 scanning electron microscope (SEM) and JEM2100 transmission electron microscope (TEM). The grain sizes were measured vertically according to $d=1.74 L$, where $L$ is the linear intercept size.

Macro-textures were determined by measuring incomplete pole figures $\left(5^{\circ} \leq a \leq 80^{\circ}\right)$ in the back reflection mode. The (0002), (1010), (1011) and (1012) pole figures were measured on the plane composed of ED and RD. The MTEX 3.0 software was used to calculate the orientation distribution function (ODF) by series expansion to $l=22$ on the basis of the spherical harmonic. The Bunge notations of the Euler angles were used throughout the characterization process. EBSD mapping was used for micro-texture measurement. The measuring area was $126 \mu \mathrm{m} \times 180 \mu \mathrm{m}$ in the step lengths of $0.2 \mu \mathrm{m}$ for $x$ direction and $y$ direction. The information of orientation maps was collected on an H-3400 scanning electron microscope equipped with an electron backscatter diffraction analysis system (TSL).

\section{Results and Discussion}

\subsection{Optical microstructures}

Fig.1 is the SEM microstructure of the as-extruded Mg-9Gd-4Y-0.6Zr alloy. It can be seen that the as-extruded alloy has equiaxed grains with the size of approximate $10 \mu \mathrm{m}$, and that a number of second phases are distributed along ED. Fig.2 shows the optical microstructures of the as-extruded alloy annealed at various temperatures for different durations. The variation of average grain sizes under various conditions is presented in Fig.3.

As shown in Fig.2 and Fig.3, the grain sizes become coarser with the increase of annealing temperature and holding time. A large amount of plate-shaped phases precipitate within grains at 623 and $673 \mathrm{~K}$, while only small particles distribute uniformly at 723 and $758 \mathrm{~K}$. It was confirmed by Zhang et $\mathrm{al}^{[11]}$ that the plate phases were $\beta$ phases $\left(\operatorname{Mg}_{5}(\mathrm{Gd}, \mathrm{Y})\right)$ and precipitated in the range of $596 \mathrm{~K}$ to $701 \mathrm{~K}$. Fig.3 shows that

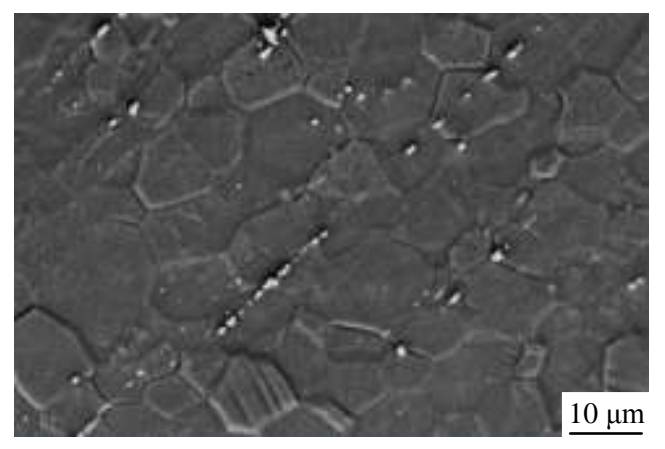

Fig.1 SEM micrograph of the as-extruded Mg-Gd-Y-Zr alloy the grain size drops sharply at static annealing for $0.5 \mathrm{~h}$ before the onset of rapid coarsening, suggesting that the SRX can be induced by the storage energy arisen from extrusion deformation. This phenomenon has been seldom observed in the low alloyed Mg alloys such as AZ31 or AM30.

\subsection{SEM micrographs}

Fig.4 presents the SEM micrographs for the annealed alloy at $673 \mathrm{~K}$ for $0.5 \mathrm{~h}$. The annealing leads to bimodal grain structures, with fine grain regions as a result of particle pinning.

Obviously, lots of second phases precipitate within grains and on grain boundaries (GBs). Fig.4b is the micrograph of the square region marked in Fig. $4 \mathrm{a}$ at higher magnification. It is interesting to note that fine grained regions occur on primary GBs and precipitates make fine grains become distinctive.

It is generally thought that the second phase particles and solute atoms involved in the extrusion deformation are expected to hinder dynamic recrystallization by dragging subgrain/grain boundaries. Hence, the processing parameters for extrusion can influence the proceeding of dynamic recrystallization ${ }^{[12]}$. In the present work, the as-extruded microstructure is free of fine grained region (Fig.1). Therefore, the fine grained regions are attributable to the recrystallization process during the initial static heating (Fig.2 and Fig.3). The driving force that is inherited from extrusion deformation results in the drop of grain size. For the high level RE-containing $\mathrm{Mg}$ alloys, the precipitating is expected to preferentially take place within the regions which are often in correspondence with strain concentrating regions. (Fig.4a, 4b). In turn the precipitates within the regions inhibit the recrystallization process, i.e. the fine grained regions result from the insufficiently recrystallized grains (IRG).

\subsection{Texture characterization}

Fig. 5 shows the ODF at the sections of $\varphi_{2}=0^{\circ}$ and $30^{\circ}$ for the deformed alloy at different annealing stages. As shown in the section $\varphi_{2}=0^{\circ}$ in Fig. 5a, the main texture components are the conventional basal fiber (BF) with $\{0001\}$ parallel to ED and the unusual prismatic fiber (PF) with $c$ axis parallel to ED. The component of PF was also observed by other researchers ${ }^{[12-14]}$. With the increase of annealing time, both $\mathrm{BF}$ and PF tend to be weakened slightly, as shown in Fig.5b 5c. It should be emphasized that there is no distinct difference between Fig. $5 b$ and Fig. 5c. This finding is different from the Mg-Al-Zn alloys in which texture is remarkably weakened after post-extrusion heat treatment ${ }^{[15]}$. Meanwhile, the two fiber components show a strong tendency to concentrate on the certain crystal directions. As a result, the peaks of $\mathrm{BF}$ and $\mathrm{PF}$ are split into $\mathrm{BF} 1$ and $\mathrm{BF} 2$, $\mathrm{PF} 1$ and PF2, respectively. The crystal rotations about $c$ axis can be attributed to recrystallization ${ }^{[16]}$.

\subsection{EBSD analysis}

The micro-texture was characterized by EBSD technique. Fig.6 illustrates EBSD results for the specimen annealed at 673 $\mathrm{K}$ for $0.5 \mathrm{~h}$. The image quality map shows that there are extensive IRG regions in the measured area in which static 


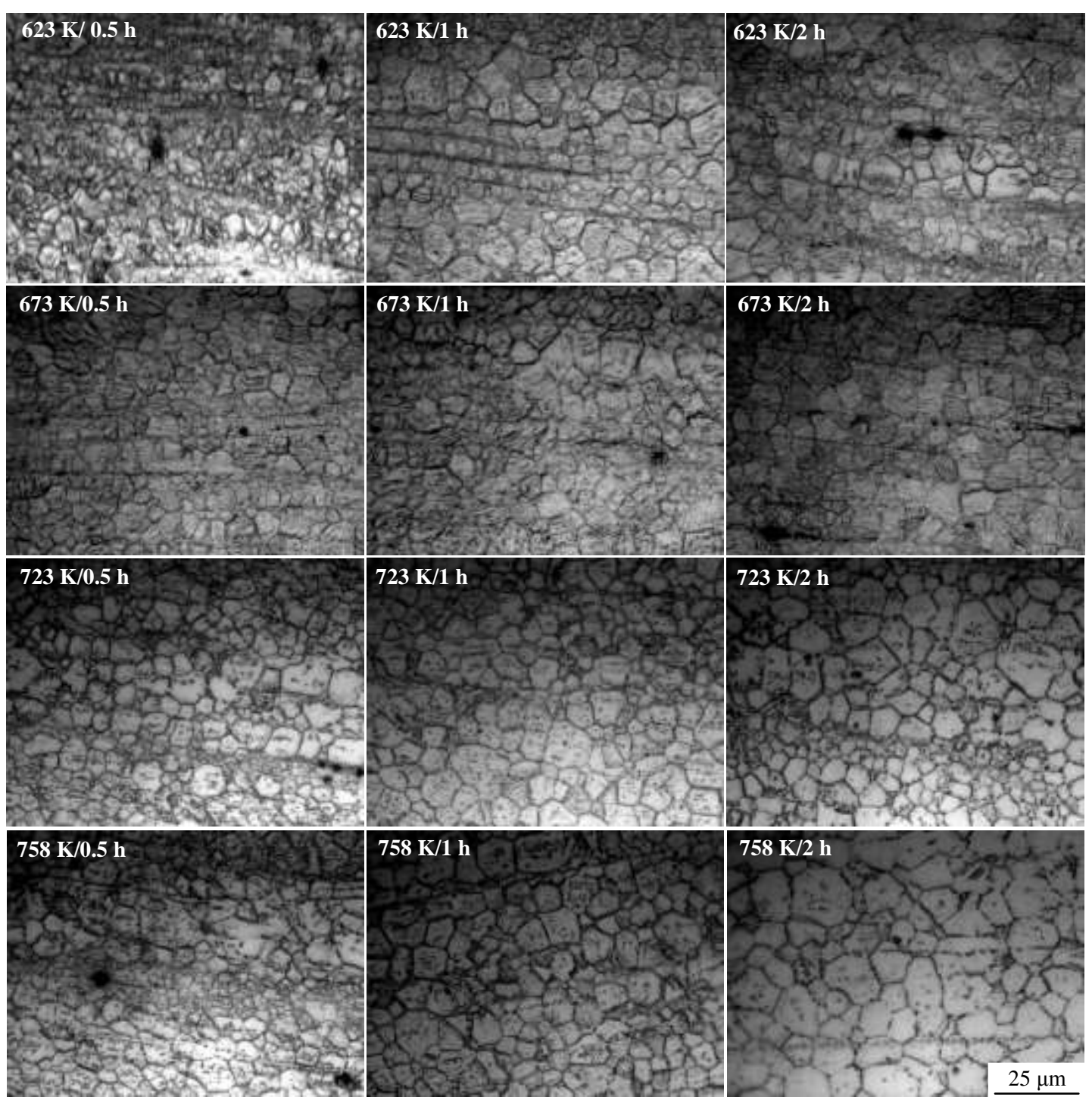

Fig.2 Microstructural evolution during static annealing at different temperatures for different durations

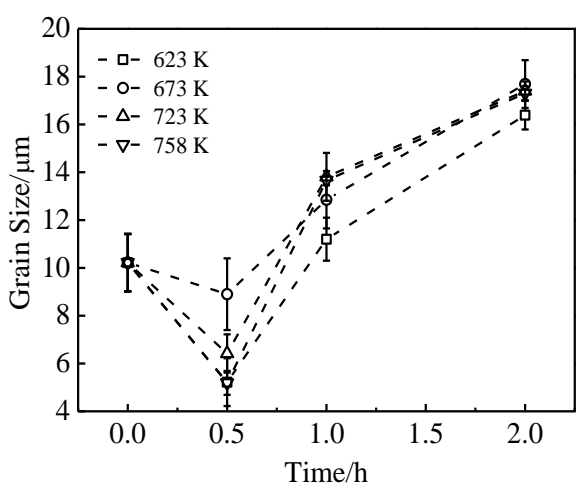

Fig.3 Variation of averaged grain sizes with time during static annealing at various temperatures

recrystallization proceeds insufficiently. This is in good agreement with the SEM morphology shown in Fig.4. It should be mentioned that the precipitates give rise to the low value of image quality within the regions.

In order to show the texture difference between the recrystallized and the insufficiently recrystallized, the full $\alpha-\mathrm{Mg}$ map in Fig. 6 was partitioned into two maps according to image quality value $(I Q)$, i.e. the recrystallized map in Fig.7 $(I Q \geqslant 58)$ and IRGs map in Fig.8 $(I Q<58)$. Fig.7 presents the orientation map and ODF at the sections of $\varphi_{2}=0^{\circ}$ and $30^{\circ}$ for the recrystallized regions that exclude the IRGs. The recrystallized regions exhibit a strong texture, i.e. ED $/ /<0001>$. Obviously, this is consistent with one of XRD texture components. Fig.8 illustrates the orientation map and ODF at the sections of $\varphi_{2}=0^{\circ}$ and $30^{\circ}$ for IRGs. As shown in Fig.8b, the dominant texture is also PF, though it is not as strong as that in recrystallized regions.

It is noted in Fig. $8 \mathrm{~b}$ that the partition shows the preferred orientations with $c$ axis parallel to ED. Since the texturemodification effect of RE additions primarily focuses on the recrystallization behavior, the effect of static annealing on 


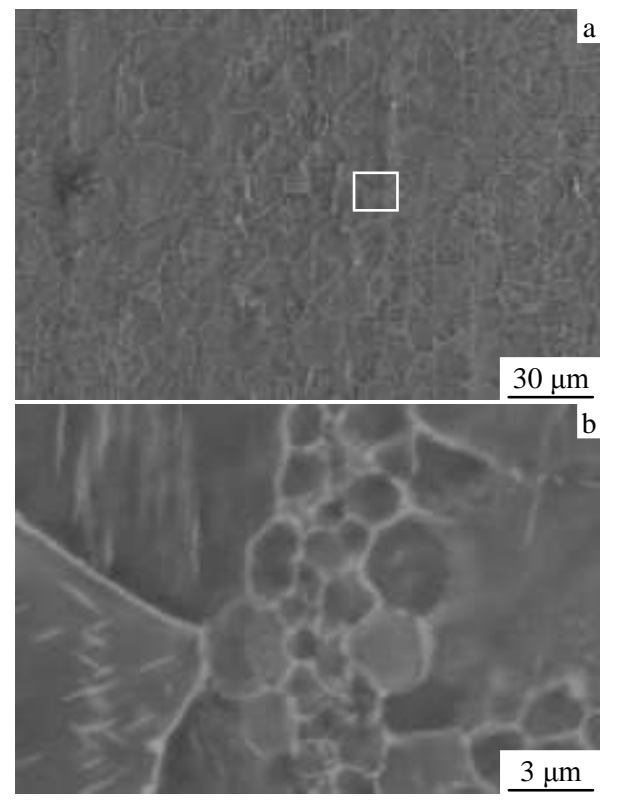

Fig.4 SEM images for the extruded Mg-Gd-Y-Zr alloy: (a) annealed microstructure at $673 \mathrm{~K}$ for $0.5 \mathrm{~h}$; (b) micrograph of the square region marked in Fig.4a at higher magnification
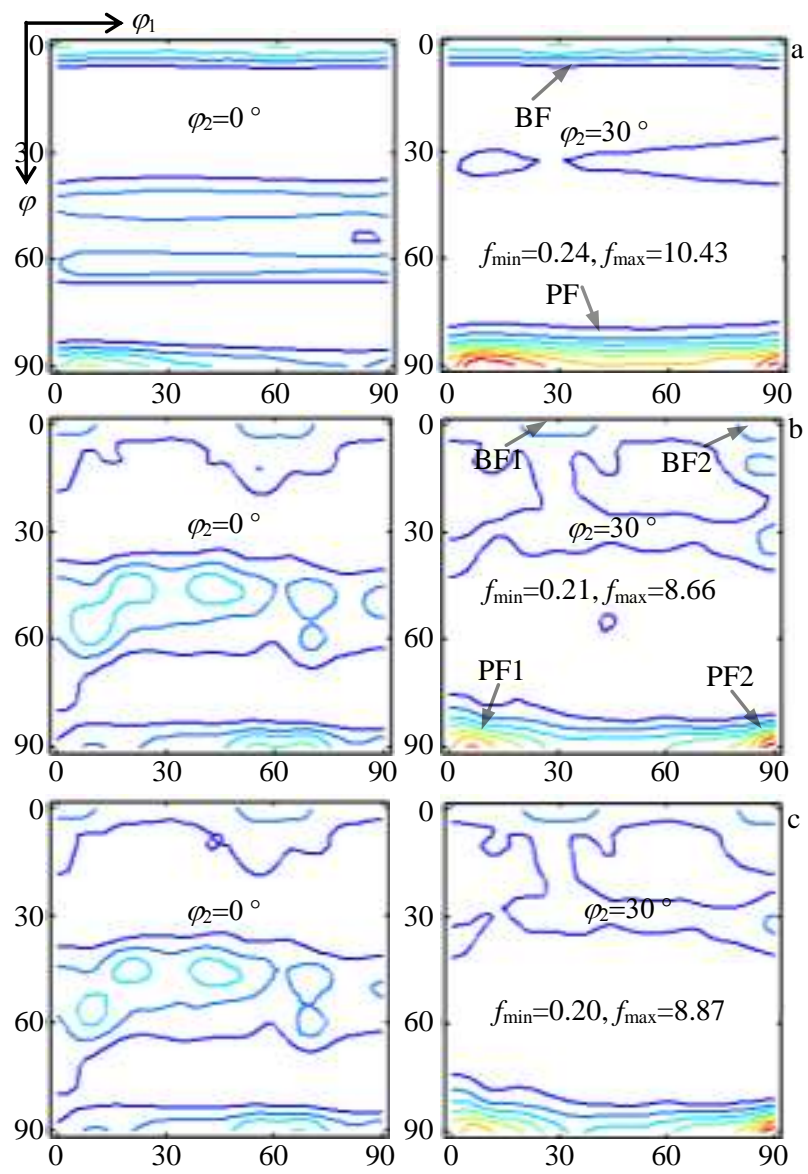

Fig.5 Orientation distribution function (ODF) at the sections of $\varphi_{2}=0^{\circ}$ and $30^{\circ}$ for the extruded alloy: (a) as extruded state, (b) annealed for $0.5 \mathrm{~h}$, and (c) annealed for $1 \mathrm{~h}$

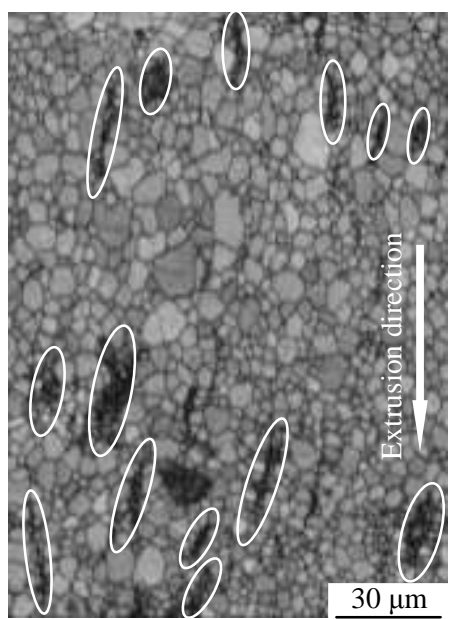

Fig.6 Image quality map of EBSD result for the specimen annealed at $673 \mathrm{~K}$ for $0.5 \mathrm{~h}$
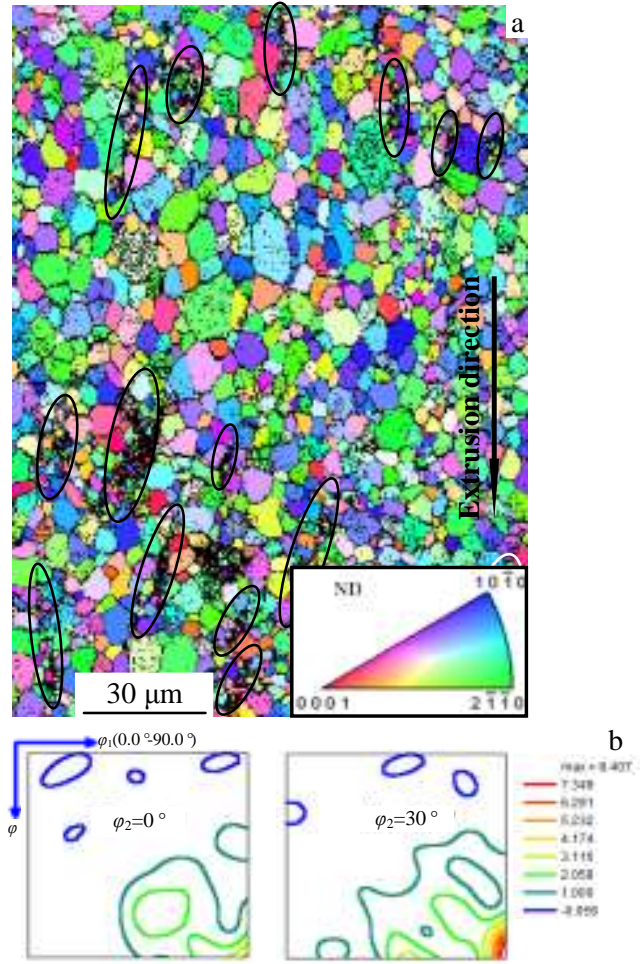

Fig.7 Recrystallized regions of the specimen annealed at $673 \mathrm{~K}$ for $0.5 \mathrm{~h}$ : (a) orientation map and (b) ODF at the sections of $\varphi_{2}=$ $0^{\circ}$ and $30^{\circ}$

texture is usually related to grain nucleation and grain growth. It can be seen from Fig.3 that static annealing can decrease grain sizes, suggesting that the recrystallization is dominated by new grain nucleation rather than grains growth. The grain nucleation process produces the relatively randomized texture within IRGs regions (in Fig.8), which weakens PF and BF. From the different texture components between recrystallized regions and IRG regions (Fig.7 and Fig.8), it can be deduced that the grain 


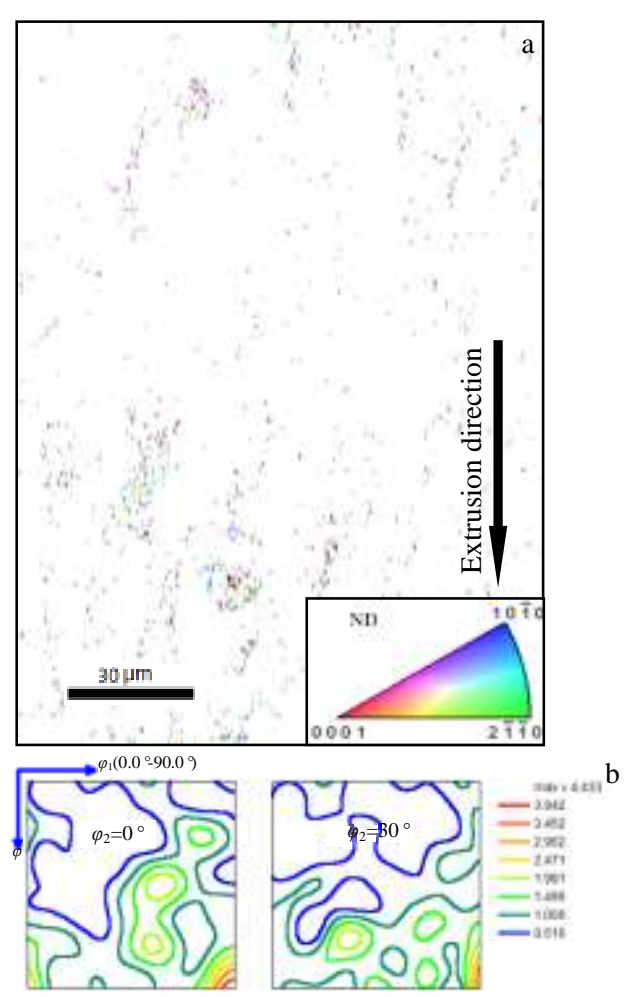

Fig.8 Insufficiently recrystallized regions of the extruded alloy annealed at $673 \mathrm{~K}$ for $0.5 \mathrm{~h}$ : (a) orientation map and (b) ODF at the sections of $\varphi_{2}=0^{\circ}$ and $30^{\circ}$

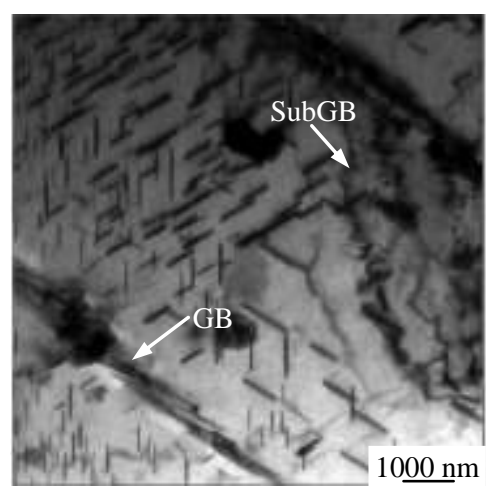

Fig.9 TEM image for the extruded alloy annealed at $673 \mathrm{~K}$ for $0.5 \mathrm{~h}$

growth process can strengthen the PF component. This can be further confirmed by the evidence that the PF component tends to be slightly stronger after the annealing for $1 \mathrm{~h}$ in comparison with that annealed for $0.5 \mathrm{~h}$ (Fig.5b and Fig.5c).

\subsection{TEM analysis}

Fig.9 presents the TEM image for the alloy annealed at 673 $\mathrm{K}$ for $0.5 \mathrm{~h}$. It can be seen that a large number of plate phases precipitate at the GBs, as well as at the subgrain boundaries. It is widely believed that the GB mobility strongly depends on the GB crystallography and material purity ${ }^{[17]}$. As the $\beta$ phases are thermally stable, they can inhibit the conversion and migration of subgrain boundaries significantly and give rise to stable textures during annealing from $0.5 \mathrm{~h}$ to $1 \mathrm{~h}$.

\section{Conclusions}

1) The drop of grain sizes during the initial annealing stage is due to recrystallization. The new subgrain/grain boundaries stimulate precipitation; in turn the precipitates on boundaries inhibit the recrystallization process.

2) The hot extrusion produces the conventional basal fiber and the unusual prismatic fiber with $c$ axis // ED. The grain nucleation process weakens the prismatic fiber, while the grain growth process strengthens it.

3) A large number of plate phases precipitate at grain boundaries and subgrain boundaries, which significantly inhibit their migration.

\section{References}

1 Bettles C, Gibson M. JOM[J], 2005, 57(5): 46

2 Pekguleryuz M O. Current Developments in Wrought Magnesium Alloys $[\mathrm{M}]$. Cambridge: Woodhead Publishing Limited, 2012: 3

3 Masoumi M, Zarandi F, Pekguleryuz M O. Scripta Materialia[J], 2010, 62(11): 823

4 Sun D K, Chang C P, Kao P W. Materials Science and Engineering $A[\mathrm{~J}], 2010,527(26): 7050$

5 Cottam R, Robson J, Lorimer G et al. Materials Science and Engineering $A[\mathrm{~J}], 2008,485(1-2): 375$

6 Ion S E, Humphreys F J, White S H. Acta Metallurgica[J], 1982, 30(10): 1909

7 Robson J D, Twier A M, Lorimer G W et al. Materials Science and Engineering $A[\mathrm{~J}], 2011,528(24): 7247$

8 Laser T, Hartig C, Ebeling T et al. Magnesium Technology, Conference[C]. New Orleans LA: TMS, 2008: 283

9 Liu H, Xue F, Bai J et al. Rare Metal Materials and Engineering[J], 2014, 43(3): 570

10 Li X, Qi W, Zheng K et al. Journal of Magnesium and Alloys[J], 2013, 1(1): 54

11 Zhang X, Li L, Deng Y et al. Journal of Alloys and Compounds[J], 2009, 481(1-2): 296

12 Robson J D, Twier A M, Lorimer G W et al. Materials Science and Engineering $A[\mathrm{~J}], 2011,528(24): 7247$

13 Chi Y Q, Zheng M Y, Xu C et al. Materials Science and Engineering A[J], 2013, 565(6): 112

14 Li L, Zhang X, Tang C et al. Materials Science and Engineering $A[\mathrm{~J}], 2010,527(4-5): 1266$

15 Shahzad M, Qureshi A H, Waqas H et al. Materials \& Design[J], 2013, 51: 879

16 Beausir B, Suwas S, Toth L S et al. Acta Materialia[J], 2008, 56(2): 200

17 Molodov D A, Czubayko U, Gottstein G et al. Acta Materialia[J], 1998, 46(2): 553 


\title{
静态退火对 Mg-Gd-Y-Zr 挤压合金微结构与织构的影响
}

\author{
李 理 ${ }^{1,2}$, 伍 ${ }^{\text {杰 }}{ }^{1}$, 吴远志 ${ }^{1}$, Nguyen Dang $\mathrm{Nam}^{2}$ \\ (1. 湖南工学院, 湖南 衡阳 421002) \\ (2. Deakin University, Geelong, Victoria 3220, Australia)
}

\begin{abstract}
摘 要: 研究了 $\mathrm{Mg}-9 \mathrm{Gd}-4 \mathrm{Y}-0.6 \mathrm{Zr}$ 挤压合金在静态退火过程中的微结构与织构的演变。采用金相显微镜、扫描电子显微镜、透射电子显 微镜、XRD 织构测试仪及 EBSD 分析技术表征了合金的晶粒长大、析出相沉淀及织构改变。结果表明, 退火初期的晶粒细化是由再结 晶引起的; 晶间不均匀变形诱发了晶间的局部析出, 继而抑制了再结晶过程。织构分析表明, 热挤压产生了常见的基面纤维织构和不常 见的柱面纤维织构, 即 $c$ 轴平行于挤压方向; 在静态再结晶过程中, 新晶粒形核会弱化柱面纤维, 而晶粒长大过程会强化柱面纤维。晶 界与亚晶界上的大量析出相抑制了织构改变。
\end{abstract}

关键词: Mg-Gd-Y-Zr 合金; 挤压; 静态退火; 织构; 微结构

作者简介: 李 理, 男, 1977 年生, 博士, 副教授, 湖南工学院先进制造技术研究所, 湖南 衡阳 421002, 电话: 0734-3452206, E-mail: lileewin@163.com 